\title{
REFLEXÕES ACERCA DO CONHECIMENTO, ATITUDES E OPINIÕES DE PROFESSORES SOBRE O BULLYING
}

\section{REFLECTIONS ON KNOWLEDGE, ATTITUDES AND TEACHER'S OPINIONS ABOUT BULLYING}

\section{RESUMO}

Marcelo Reis Clemente ${ }^{1}$, Dalva Alves Silva², Maria Sylvia de Souza Vitalle ${ }^{3}$

Este estudo teve por objetivo analisar a percepção de professores de duas escolas da rede pública de ensino do Município de Guarulhos (Educação Básica - Ciclo I, $5^{\circ}$ Ano e Ciclo II, $6^{\circ}$ ao $9^{\circ}$ Ano -), a respeito do fenômeno bullying nas escolas, procurando identificar o conhecimento, a opinião e atitudes de professores sobre o tema bullying envolvendo adolescentes, levantar informações a respeito do preparo que os professores receberam em sua formação para lidar o bullying e conhecer as orientações e/ou protocolos específicos a serem seguidos pelos professores e equipe escolar nas instituições estudadas em casos de bullying envolvendo adolescentes. Foi realizado um estudo qualitativo, empírico observacional por meio de entrevistas presenciais, gravadas, transcritas e analisadas pela análise de conteúdo. Os resultados obtidos apontam a necessidade de realização de palestras, cursos e treinamentos envolvendo o conhecimento do bullying e suas consequências, bem como estratégias de enfrentamento que auxiliem os professores para práticas de prevenção e erradicação do bullying nas instituições onde atuam.

PALAVRAS-CHAVE: Educação. Bullying. Violência escolar. Treinamento de professores.

\section{ABSTRACT}

This study aims to analyze the perception of teachers from two public schools in the Guarulhos city (Elementary 5th to 9th grades), regarding the bullying phenomenon in schools, trying to identify the knowledge, opinion and attitudes of teachers on the matter of bullying involving adolescents, to raise information about the preparation that teachers received in their training to deal with bullying and to know the specific guidelines and / or protocols to be followed by teachers and school staff in the institutions studied in cases of bullying involving adolescents. A qualitative, empirical observational study was conducted through face-to-face interviews, recorded, transcribed and analyzed by content observation. The results show the need for lectures, courses and trainings involving the awareness of bullying and its consequences, as well as coping strategies that help teachers to prevent and eradicate bullying in the institutions where they work.

KEYWORDS: Education. Bullying. School violence. Teacher's training.

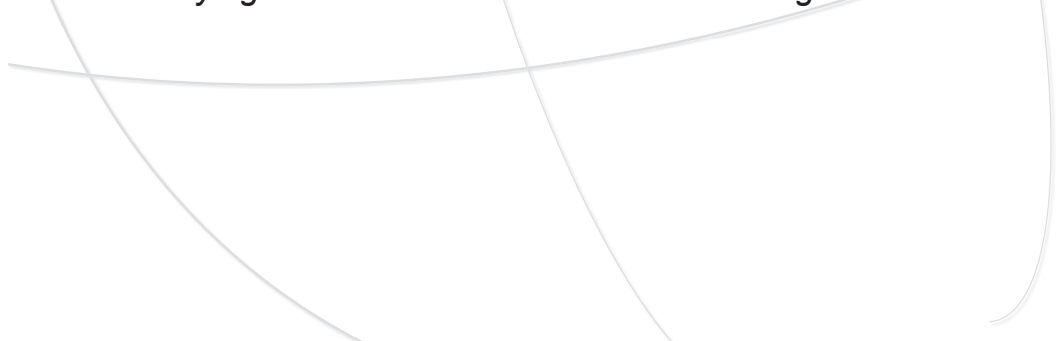

1 Mestre em Ciências: Educação e Saúde na Infância e na Adolescência pela Universidade Federal de São Paulo - Unifesp. Docente da Faculdade das Américas - FAM.

2 Doutora em Ciências: Educação e Saúde na Infância e na Adolescência; pedagoga e psicopedagoga, colaboradora no Setor de Medicina do Adolescente/Unifesp.

3 Profa. Adjunto Doutora do Setor de Medicina, Unifesp; Professor permanente do Programa de Pós-Graduação Educação e Saúde na Infância e na Adolescência. Autora Correspondente: Maria Sylvia de Souza Vitalle Setor de Medicina do Adolescente/ Departamento de Pediatria, Universidade Federal de São Paulo - Unifesp. Endereço: Rua Botucatu, 715, Vila Clementino, CEP 04023-062, São Paulo, SP, Brasil. E-mail: sylviavitalle@gmail.com 


\section{Introdução}

A sociedade atribui à escola o papel social de transmissora de conhecimentos sistematizados e organizados, assim como a transmissão de valores culturais, normas comportamentais e sociais. A escola é uma ponte entre a família e a sociedade. Idealmente, família e escola deveriam estabelecer uma relação de confiança e parceria na educação de crianças e adolescentes.

A escola é um lugar onde crianças e adolescentes aprendem não somente conteúdos acadêmicos e culturais, mas, sobretudo, aprendem a viver em conjunto e a lidar com os diferentes jeitos de ser de outras crianças, adolescentes e adultos, além de aprender a formar novos vínculos afetivos, principalmente, entre pares, que poderão durar por toda a vida. Na família e na escola as crianças e os adolescentes aprendem sobre direitos e deveres e a se tornar cidadãos. A Educação é um benefício e um direito fundamental para crianças e adolescentes, que precisam de um ambiente seguro para que possam aprender e se beneficiar de tudo que a educação possa Ihes oferecer. Esforços globais têm sido feitos para práticas como a violência escolar e o bullying não violem a garantia desses direitos (UNESCO / 2017).

Paranahiba \& Paranahiba (2016), em artigo intitulado "O uso do ECA no combate ao Bullying", alertam para o perigo de se negligenciar práticas de bullying no ambiente escolar:

(...) o bullying não pode ser negligenciado, como se consistisse em insignificantes brincadeiras de crianças e adolescentes, que logo passarão, sem deixar sequelas. Erro crasso! Se não for diligentemente tratado, como um comportamento antissocial, ofensivo e deletério, consequências adversas sobrevirão na fase adulta.(p. 377).

A maior agravante, não descrita no ordenamento jurídico, é a consequência nefasta na formação da criança e do adolescente, visto que a escola é considerada um dos primeiros e mais importantes ambientes sociais para o desenvolvimento integral. A vivência de agressões, sem o devido acolhimento do agredido, sem orientação ao agressor, poderá causar uma marca indelével e traumática durante seu desenvol- vimento, com sérias repercussões na fase adulta. Baixa autoestima, timidez exacerbada, dificuldade de relacionamento, e depressão são alguns sintomas que podem fazer parte da vida de adultos que sofreram bullying.(p. 378).

Em todo e qualquer agrupamento humano os conflitos estão presentes e lidar com eles faz parte dos aprendizados que a convivência no ambiente escolar pode proporcionar. A escola é um lugar propício à aprendizagem de inúmeras habilidades e atitudes, dentre elas, as de relacionamento. Nas palavras de Pedroso $(2019$, p.506) "Os conflitos fazem parte da vida na escola, cabendo ao educador proporcionar o aprendizado e desenvolvimento de habilidades dos alunos para solucioná-los". No entanto, Girodani, Saffner e Dell'Aglio (2017) encontraram em seu estudo, que os professores referem que não se sentem preparados profissionalmente, para lidar com situações de conflito no ambiente da escola e efetivamente atuar na prevenção, enfrentamento e resolução de situações de violência.

Pela falta de apoio aos professores, por parte de famílias e de alguns gestores educacionais, as agressões deixam de ser comportamentos excepcionais e raros e vão sendo cada vez mais corriqueiros, bem como naturalizados no ambiente escolar.

Neste sentido, cada vez mais, tem-se observado que os professores estão encontrando dificuldades para lidar com os conflitos e as questões de disciplina e comportamentos inadequados, na sala de aula e dependências da escola, pois eles mesmos, os professores, acabam por se tornar alvos desses comportamentos dos alunos. Um artigo publicado pelo Centro do Professorado Paulista (BERTO, 2018), mostra que, segundo a Organização para a Cooperação e Desenvolvimento Econômico - OCDE, "o Brasil tem o pior índice no mundo quando o assunto é violência contra professores", sendo que este problema abrange tanto escolas públicas como privadas. Para o autor, a responsabilidade na construção de valores, na aquisição de habilidades e atitudes de gentileza, respeito e sociabilidade é uma tarefa primordialmente cabível às famílias. À escola cabe reforçar estas habilidades e atitudes, assim como propor atividades que levem seus alunos à expressão de tais habilidades e valores.

Desse modo, não seria exagero considerar que 
os professores de escolas públicas trabalham sob pressão: classes cheias, muitas turmas, muitas vezes, ministrando aulas em outras escolas. Somando-se a isso, há, ainda, a desvalorização da carreira (social e financeira), a formação que não os prepara para lidar com os conteúdos acadêmicos a serem ensinados ao longo do ano letivo, diante da falta de foco e indisciplina dos alunos, das situações de bullying e dos comportamentos agressivos de alguns alunos dirigidos a seus pares e a eles, os próprios professores.

Contudo, para que as ações de prevenção do bullying, como para outros tipos de agressões, tornase importante que os professores fiquem atentos aos comportamentos apresentados pelos alunos e reconheçam essas práticas no ambiente escolar, no entanto, se percebe uma inabilidade de alguns professores e escolas para ações de prevenção mais efetivas (SANTOS, 2014). Como os adolescentes, vítimas de bullying, não apresentam, na maioria dos casos, marcas corporais de agressões físicas que possam chamar a atenção dos pais, professores e demais agentes escolares, a situação pode passar quase despercebida. Assim, observando atentamente, é possível verificar se os adolescentes apresentam sinais de alerta, tais como: alteração de comportamento, mudança de hábitos, que podem apontar para a ocorrência de algum tipo de violência doméstica, ou de agressão no espaço escolar, que sinalize algum envolvimento em caso de bullying, seja como agressor, vítima ou testemunha de um ato agressivo (PEDROSO, 2019).

Dentre as situações de violência na escola, o bullying se distingue por se tratar de "práticas de intimidação sistemática (bullying), quando há violência física ou psicológica em atos de intimidação, humilhação ou discriminação" (LEI FEDERAL № 13.185/2015, Art. ${ }^{\circ} 2^{\circ}$ ), com a intenção de humilhar, de exercer poder desigual, de maneira repetitiva, que envolve, no mínimo um agressor e uma vítima, de mesma idade ou não, cujos impactos, sobretudo nos envolvidos, podem se estender ao longo de anos e incidir negativamente no desempenho acadêmico e em outras áreas da vida de ambos. Geralmente, a vítima de bullying sofre calada; é um sofrimento silencioso e solitário, assim também é com a testemunha que presencia, mas se mantém em silêncio por medo de represálias ou mesmo por apoiar tal prática. Neste sentido, são pelo menos três os envolvidos: o agressor, a vítima e a testemunha. De acordo com Santos (2014), as testemunhas podem ser de quatro tipos: as que participam da agressão, as que incentivam o agressor, as que só observam e as que protegem a vítima e buscam um adulto para ajudá-la.

Com a Lei Federal $n^{\circ} 13.185$ de 2015, foi instituído em todo o país, o Programa de Combate ao Bullying que, na presente legislação, recebeu o nome de "Intimidação Sistemática". Esta lei federal apresenta a caracterização do bullying e do cyberbullying (aquele praticado via rede mundial de computadores), apresenta uma classificação dos tipos de bullying, que o diferencia de outros tipos de violência, estabelece como objetivos fundamentais nove ações/deveres cabíveis às escolas, aos clubes e agremiações recreativas, com especial ênfase para as instituições educacionais no sentido de prevenir, combater, capacitar docentes e equipes pedagógicas, orientar pais e responsáveis, promover campanhas de educação e conscientização, diagnose e combate à intimidação sistemática, dentre outros deveres, por assim dizer, uma vez que a Lei $\mathrm{n}^{\circ}$ 9.394/96 de Diretrizes e Bases da Educação Nacional, em 2018, foi modificada em razão do bullying, com o acréscimo em seu $12^{\circ}$ Artigo de dois incisos - IX e X - reafirmando a responsabilidade das escolas quanto a criar e efetivar a implantação de medidas de conscientização, prevenção e combate a todos os tipos de violências e, em especial ao bullying, assim como criar e efetivar ações de promoção da cultura de paz.

A fim de efetivar as ações do Programa de Combate ao Bullying, proposto pela Lei Federal 13.185/2015, em seu Art. $7^{\circ}$ abre a possibilidade do estabelecimento de parcerias para a implementação do Programa instituído. Desse modo, as instituições de ensino, clubes e agremiações poderão contar com parcerias junto a equipes multiprofissionais compostas por profissionais da saúde e educação, como por exemplo, equipes de saúde do adolescente (VITALLE, SCHOEN-FERREIRA, WEILER et al., 2010), bem como contar com profissionais do direito e de outras áreas, dependendo das necessidades e do contexto.

Não há dúvidas que a rotina de trabalho em uma escola pode ser extenuante e cansativa, quando o profissional da educação tem de lidar com demandas de trabalho que, muitas vezes, extrapolam a própria formação que recebeu. Temas como violência juvenil, vio- 
lência escolar e o bullying, que têm se tornado ações cotidianas dentro do ambiente escolar, não são temas abordados com frequência na formação desse profissional. O ambiente escolar, que deveria ser calmo, seguro e acolhedor, em boa parte das vezes, torna-se um ambiente hostil não apenas para os alunos, mas também para o professor. Ao pensarmos nesta realidade, qual seria o papel do professor em relação a estes temas de abrangência social e comunitária dentro do espaço escolar? Estaria de fato este profissional capacitado e qualificado para além de suas atividades de docência, que já consomem muito de suas energias, a dar conta também das questões de disciplina? Qual seria sua atuação frente a uma situação de bullying envolvendo adolescentes? Quais seriam as providências a serem tomadas? Existem protocolos específicos nas escolas sobre o atendimento e encaminhamento de adolescentes vítimas, agressores ou testemunhas de bullying?

Este estudo teve por objetivo de refletir sobre o conhecimento que os professores têm a respeito do bullying, atitudes e algumas opiniões frente a esse fenômeno.

\section{Percurso metodológico}

Este artigo é produto da Dissertação de Mestrado do primeiro autor. Trata-se de um estudo qualitativo, empírico, observacional, que envolveu dezesseis professores de duas escolas públicas de Educação Básica - Ciclo I, $5^{\circ}$ Ano e Ciclo II, $6^{\circ}$ ao $9^{\circ}$ Ano - da Rede Municipal de Ensino de Guarulhos. Participaram dezesseis professores, sendo oito de cada uma das duas escolas que aceitaram que seus professores respondessem a entrevista semiestruturada composta de vinte questões norteadoras. As respostas foram gravadas, com autorização dos entrevistados, transcritas, ouvidas uma vez e outras vezes, lidas, relidas, conforme a análise de conteúdo preconiza (BARDIN, 2011). Como base, seis questões foram extraídas para este artigo, como representativas de três eixos de análise temática: 1) o conhecimento que os professores têm a respeito do bullying; 2) a opinião que os professores têm a respeito do bullying; e 3) as atitudes dos professores frente às práticas de bullying; a saber: a) tempo de formação e tempo de atuação nas escolas que aceitaram participar do estudo; b) conhecimento dos professores a respeito do bullying; c) opinião dos professores sobre diminuir e/ou erradicar o bullying nas escolas; d) atitudes frente a práticas de bullying envolvendo adolescentes; e) preparo dos professores e da equipe escolar para lidarem com o bullying entre adolescentes; e, f) orientações e/ou protocolos institucionais a serem seguidos pelos professores e equipe escolar em casos de bullying na escola.

\section{Aspectos éticos}

Quanto aos aspectos éticos, a pesquisa de mestrado, intitulada: "Conhecimentos, opiniões e atitudes de professores e pediatras da rede pública do município de Guarulhos sobre bullying em adolescentes - uma contribuição para o estudo do bullying", foi realizada de acordo com a Resolução n 466/12, do Conselho Nacional de Saúde do Ministério da Saúde, que regulamenta as pesquisas envolvendo seres humanos, tendo sido devidamente inscrita na Plataforma Brasil - Comissão Nacional de Ética em Pesquisa CONEP, e aprovada conforme protocolo $n^{\circ} 6762$.

Os professores participaram voluntariamente nesse estudo após o convite. A participação deles foi isenta de despesas e benefícios financeiros. $\mathrm{O}$ aceite de cada um foi firmado mediante leitura e assinatura do Termo de Consentimento Livre e Esclarecido, de acordo com as normas exigidas para as pesquisas com seres humanos, incluindo a garantia de anonimato e a garantia da liberdade de cancelamento da participação no estudo durante seu desenvolvimento se assim o desejassem por razões próprias. As Instituições escolares que concordaram em participar concederam a Declaração de aceite assinada pelo responsável da instituição.

\section{Resultados e discussão}

\section{a) Tempo de formação e tempo de atuação nas escolas que aceitaram participar do estudo}

Em relação ao tempo de formação dos professores e tempo de atuação nas escolas que aceitaram participar do estudo (Escola I e Escola II), encontramos na Escola I: um professor com quatro anos de formação, mas sem identificação do tempo de atuação na 
escola; dois professores com cinco anos de formação e cinco de atuação; dois professores com oito anos de formação e oito de atuação; um professor com vinte anos de formação e dez de atuação na escola; um professor com 21 anos de formação e onze de atuação e um professor com trinta anos de formação e trinta de atuação na escola. Na Escola II encontramos um professor com vinte e quatro anos de formado e vinte e três de atuação na escola. Os demais professores, sete ao todo, tinham o tempo de formação correspondente ao tempo de atuação na escola, a saber: um professor com três anos de formação e atuação; um com quatro anos; um com seis anos; um com dez anos; um com onze anos; um com vinte anos e, por fim, um com vinte e cinco anos de formação e atuação.

\section{b) Conhecimento dos professores a respeito do}

\section{Bullying}

O conhecimento das práticas de bullying e suas consequências têm sido presente em assuntos de redes sociais e tantos outros veículos de comunicação, tornando-se um termo um pouco mais conhecido do grande público. Segundo pesquisa sobre bullying escolar no Brasil (CEATS/FIA, 2010), realizada há quase uma década pelo Centro de Empreendedorismo Social e Administrativo em Terceiro Setor CEATS e da Fundação Instituto de Administração - FIA da Universidade de São Paulo, que ouviu 5.168 alunos de 25 escolas das cinco regiões do país, quando a palavra bullying era substituída por maus tratos, facilmente as pessoas reconheciam ações de agressões repetidas e passavam a identificar melhor o fenômeno em suas manifestações no cotidiano escolar.

Embora nos últimos anos muito se fale sobre bullying, muitos ainda não possuem uma compreensão adequada a respeito do que de fato ele significa. Contudo, contribuindo para sua compreensão, Silva et al. (2014) destacam que o conhecimento acerca deste fenômeno "tem avançado sistematicamente, tendo como base a produção científica em torno do tema" [...] "possibilitando sua caracterização de modo cada vez mais global e aprofundado (p.148)".

Além de expressar o conhecimento apropriado do conceito, os professores deveriam ao menos nomear o fenômeno segundo suas manifestações mais rotineiras e conhecidas como: agressão verbal, física e/ou psicológica praticada repetidamente contra uma pessoa com o propósito de humilhá-la e subjugá-la sob o jugo de um poder desigual. Como conhecimento insuficiente, entendemos não conceituar adequadamente o fenômeno, nem mesmo através de suas manifestações.

Ainda que algumas falas de professores pareçam não considerar a gravidade do fenômeno bullying ou não perceber que ele se distingue de outras formas de violência na escola, com expressões tais como: "Tudo agora virou bullying! Acho que é mais uma questão de moda pedagógica..." ou "Acredito que é toda manifestação de violência contra alguém", os professores entrevistados demonstraram, espontaneamente, algum conhecimento a respeito do bullying, relatando aspectos de sua definição e algumas formas de sua prática e consequências, conforme podemos observar nos Quadros 1 e 2: 


\section{Quadro 1 - Escola I: Conhecimento dos professores a} respeito do Bullying

Prof.1:

Formação: 08

Atuação: 08

Formação: 21

Atuação: 11

$p$

Prof.3:

Formação: 20

Atuação: 10

Prof.4:

Formação: 30

Atuação: 30
Eu penso que bullying é uma forma de agressão e preconceito. Pode ser uma agressão física, ou verbal ou até mesmo pela internet. Acho que jogar o material do colega no chão também é.

Acho que esse negócio de bullying não está bem colocado na sociedade. Tudo agora virou bullying. Acho que é mais uma questão de moda pedagógica. Acho que há um exagero. Mas acho que de certa forma o bullying é um preconceito que vira agressão, que vira violência, xingamentos, apelidos ofensivos e por aí vai...

Acho que é toda forma de violência contra uma pessoa. Pode ser verbal, física, até pela internet, telefone, xingamentos, apelidos depreciativos. Acho que é isso!

Acho que é bater no colega, xingar, ofender, tirar fotos e pôr na internet, ridicularizar os colegas na frente dos outros ...

\section{Prof.5:}

Formação:04

Atuação: s/

dado

Prof.6:

Formação: 05

Atuação: 05

(1)

Prof.7:

Formação: 08

Atuação: 08

Formação: 05

Atuação: 05
Acredito que é toda manifestação de violência contra alguém ... seja ela física ou verbal.

Na minha forma de ver o bullying é uma maneira que algumas pessoas utilizam para humilhar outras, colocar uma outra pessoa em uma situação de vergonha, ou até mesmo um agressão física, ou por palavras, xingamentos, apelidos...coisa assim.

Bullying é toda agressão física ou verbal...pode ser apelidos que a pessoa não goste, desprezo, humilhações. Tem também o bullying virtual, aquele que acontece através da internet...tipo colocar uma foto meio constrangedora em um blog, ou site tipo Facebook... tentando humilhar a pessoa. Adolescentes fazem muito isso!

Bullying... não sei muito sobre isso, mas acredito que é xingar, ofender, ou até bater nos outros que são diferentes, ou mais fracos... As formas? Então...acho que é agressão verbal ou até agressão física mesmo.

\section{Quadro 2 - Escola II: Conhecimento dos professores a respeito do Bullying}

Prof.1:

Formação: 24

Atuação: 23

Acredito ser uma forma de agressão, de discriminação, de constrangimento que você passa em relação a outras pessoas, pode ser discriminação racial, cor, aparência, forma de falar (...) de infinitas formas pode ser diagnosticado o bullying....acredito ser uma forma de agressão mesmo.

Prof.2:

Formação: 06

Atuação: 06

Eu acho que bullying é bater, brigar, humilhar o coleguinha...pode até acontecer fora da escola também. Colocar apelido ofensivo...estragar o material do colega.

Prof.3:

Formação: 11

Atuação: 11

Bullying no meu ponto de vista... é aquela agressão, ou xingamento contra alguém sem motivo aparente... É uma ofensa, ou agressão até física contra alguém gratuitamente, sem motivo algum.

Prof.4:

Formação: 10

Atuação: 10

Ah!...acho que são xingamentos, agressão física...xingamentos pelas redes sociais.

Prof.5:

Formação 20:

Pelo que eu sei, bullying é agressão

Atuação: 20 , xingamentos, apelidos ofensivos, né? Pode ser também agressão física, destruição do material dos colegas.

Prof.6:

Formação: 25

Atuação: 25

Pelo que eu sei, o bullying é quando uma criança ou adolescente agride um outro que seja diferente ou mais fraquinho ...é sempre o mais forte contra o mais fraco. Um jogo de poder desigual, ou quando alguém é muito diferente: quieto, gordinho, ou magrinho demais...aí os demais ficam colocando apelidos.

Prof.7:

Formação: 04

Acho que é xingar, ofender, agredir Atuação: 04

Prof.8:

Formação: 03

Atuação: 03
Bullying é uma forma de agressão e pode ser oral, verbal, ou concreta, física, inclusive estragando o material, os pertences da outra pessoa. 


\section{c) Opinião dos professores sobre diminuir e/ou erradicar o bullying nas escolas}

Diálogos, conversas, diferentes formas de conscientização a respeito dos danos causados pelas práticas de bullying, promoção de cursos e palestras para os alunos e escola como um todo, sessões de debates, colaboração da mídia em geral, participação familiar na parceria com a escola na educação dos fiIhos, parcerias entre escolas e profissionais de saúde e educação, das artes (nas suas diversas formas de expressão) e dos esportes dentre tantas outras possíveis parcerias que podem contribuir para a criação e implantação de programas e projetos que, por meio de ações efetivas, contribuam para a erradicação do bullying de escola em escola.

$\mathrm{Na}$ opinião dos professores, erradicar o bullying não é tarefa fácil e pode ser difícil de acontecer, contudo eles sinalizam que o caminho a ser seguido envolve diálogo e rever as próprias práticas em sala de aula; envolve ações de conscientização a respeito das consequências negativas do bullying; envolve os valores humanos fundamentais como a educação (em seu sentido amplo), o respeito, a atenção, a escuta sensível, a consideração do outro e seu reconhecimento na relação de uns com os outros. Os professores também se sentem vulneráveis e muitas vezes solitários diante da falta e apoio e orientação. Estas são informações importantes para os gestores e equipe escolar, sobretudo, em relação ao perigo de negligenciar o que os professores expressam e/ ou negligenciar as consequências nefastas resultantes do bullying, conforme (acima) alertam Paranahiba \& Paranahiba (2016). Vejamos os Quadros 3 e 4:

\section{Quadro 3 - Escola I: Opinião dos professores sobre diminuir e/ou erradicar o bullying nas escolas}

Prof.1:

Formação: 08

Atuação: 08

Acho que conversar sempre é o melhor caminho. Não adianta castigo, suspensão ou outra forma de punição. Rever nossas práticas em sala de aula.

Prof.2:

Formação: 21

Acho que isso nunca vai acabar... des-

Atuação: 11 de que o mundo é mundo isso existe, acho que pode diminuir à medida que tratamos sobre essas coisas, mas é só a poeira assentar, deixarmos de abordar essa questão de bullying e das agressões que começa tudo de novo.

Prof.3:

Formação: 20

Atuação: 10

Diálogo com os pais, conversar com os alunos, procurar conscientizá-los sobre o assunto, que isso não é legal, todos se prejudicam...tentar até quem sabe algo como uma punição educativa, talvez colocar o que agrediu para ajudar alguém que está ruim em alguma matéria, colocar para ajudar alguém na escola ou fazer alguma coisa...algo mais ou menos assim.

Prof.4:

Formação: 30

Penso que a escola deve promover sem-

Atuação: 30 pre cursos, palestras, para que ninguém se envolva com o bullying. Devemos sempre conversar, procurar um diálogo com os alunos, mostrando que isso prejudica todo mundo.

Prof.5:

Formação:04

Atuação: s/dado

Prof.6:

Formação: 05

Atuação: 05

Educação! Ensino, orientação, muita instrução, inclusive aos pais, para que eduquem no âmbito familiar.

Olha não sei se isso vai acabar, mas acho que é possível diminuir sim! (...) com muitas atividades simultâneas, debates, peças de teatro, projetos da escola...né? Trabalhos em sala de aula... dessa forma acho que podemos diminuir muito a prática dessa violência entre os estudantes. É uma solução que não é mágica, sei que não é fácil, demora bastante para você conseguir mudar os hábitos, costumes...das pessoas.

Prof.7:

Formação: 08

Atuação: 08
Olha não sei ao certo....acredito novamente que através de um conjunto de ações como palestras, debates.... ensino...é a educação, né?...tem que conversar muito sobre isso. Acabar, não sei se vamos conseguir... acho que não! Mas diminuir acho que é possível, sim!

Prof.8:

Formação: 05

Atuação: 05
Não sei não...acho que podemos até conseguir diminuir essas práticas, mas erradicar, terminar com isso...tenho dúvidas. Porque acho que faz parte do ser humano, sabe? Quem já não foi vítima de bullying? Acho que todo mundo já foi, mas acho que dá sim para diminuir. Devemos tratar os alunos com respeito e ensiná-los a tratarem os outros, também com respeito e consideração. Acho que desse jeito, construiremos uma sociedade melhor e pessoas com mais conscientização sobre o que é de fato cidadania. 


\section{Quadro 4 - Escola II - Opinião dos professores sobre diminuir e/ou erradicar o bullying nas escolas}

Prof.1:

Formação: 24

Atuação: 23
Prof.2:

Formação: 06

Atuação: 06
Olha, é...eu acho que tudo parte da formação. Da formação do indivíduo, da formação do profissional que trabalha com isso, das mídias. O professor por exemplo (...) eu me vejo nessa posição: uma professora com vinte e três anos de profissão e que pouco sabe sobre o assunto e quando se vê nessa situação, fica até meio perdida... os acessos a essas ajudas são poucos, são mínimos, você não sabe exatamente quem procurar, o que falar...você vai procurar um diretor, o diretor às vezes não está preparado pra te dar essa resposta.

Acho muito difícil erradicar, mas acho que poderemos conseguir que a prática seja desencorajada e que diminua gradativamente ao longo do tempo...penso que diversas medidas são importantes e úteis, como seminários para os professores e demais agentes escolares, muito diálogo e conversa com os alunos.

Prof.3:

Formação: 11

Atuação: 11

Prof.4:

Formação: 10

Atuação: 10

Prof.5:

Formação 20:

Atuação: 20

Prof.6:

Formação: 25

Atuação: 25

Prof.7:

Formação: 04

Atuação: 04

rof.8:

Formação: 03

Atuação: 03
Acredito que conversar sempre sobre estas questões, realizar trabalhos diversos em sala de aula, teatro... envolver a escola nisso, realizar um projeto que atravesse o ano inteiro ... acho que medidas assim podem contribuir para minimizar esta situação.

Acho que uma reunião com todo o grupo, mostrando que isso não é legal. Conversar, falar, sugerir leituras, talvez passar um filme e depois conversar sobre o filme, fazer debates.

Acho que isso é difícil (diminuir/erradicar), mas o caminho é o mesmo...Conversa, debates, cursos de capacitação para os educadores...envolver família e toda a comunidade escolar.

Acho que a Secretaria da Educação e o MEC (Ministério da Educação e Cultura), deveriam fazer uma cartilha, bem legal, ilustrada e promover campanhas bem chamativas na televisão e projetos nas escolas.

Palestras, cursos de capacitação para os professores, envolver alunos, pais e gestores...realizar eventos diversos, palestras, peças de teatro, concurso musical....tentar de todas as formas conscientizar a todos.

Acho que erradicar é impossível, mas podemos contribuir para diminuir sim. Ah!... acho que a escola deve promover uma série de eventos, cursos, palestras...investir na capacitação dos professores que passam a maior parte do tempo com os alunos... os professores devem ser treinados para enfrentar esse problema.

Conversas periódicas sobre $o$ assunto $e$ realização de projetos de longa duração e que envolvam todas a escola, professores, direção, coordenação, alunos e pais.

\section{d) Atitudes frente a práticas de bullying envolvendo adolescentes}

Por meio dos relatos é possível observar que os dois grupos de professores consideram o diálogo como atitude principal quanto ao enfrentamento de conflitos entre adolescentes envolvidos em casos de bullying. Alguns dos respondentes acrescentaram que, junto às conversas e ao diálogo, uma atitude a ser tomada deveria a repreensão, no sentido de contenção de alguns comportamentos. O encaminhamento à direção da escola, o contato com as famílias e o encaminhamento à terapia psicológica também estão entre as atitudes consideradas importantes pelos professores. Mas, muito interessantes são as formas relatadas por vários deles a respeito de como lidam/lidaram com situações que poderiam se caracterizar como bullying ou mesmo evoluir para tal, como nos mostram alguns relatos de professores das duas escolas tanto para diminuir ou erradicar o bullying, como em relação a atitudes a serem tomadas no contexto da própria sala de aula, conforme podemos observar nos Quadros 3 e 4 (acima) e 5 e 6 a seguir:

\section{Quadro 5 - Escola I: Atitudes dos professores frente a práticas de bullying envolvendo adolescentes}

Prof.1: $\quad$ Conversar, interromper a agressão, chamar Formação: 08 a atenção de quem estava agredindo e proAtuação: 08 curar apaziguar a situação. Já levei casos assim à direção, e o diretor não resolve nada. Teve uma vez, que o diretor aplicou até uma suspensão no aluno. Isso nem é legal. É proibido, mas fazer o quê? Tem casos que nem o diretor aguenta mais.

Prof.2:

Formação: 21

Atuação: 11

Procuro amenizar a situação e procurar descobrir o porquê do comportamento agressivo e chamar os envolvidos para uma conversa em particular (...) acho que é por aí.

Prof.3:

Formação: 20

Atuação: 10
Houve um caso de uma aluna que não sabia ler e eu percebi que os outros alunos de certa forma procuravam colocar ela em uma situação de chacota, riam dela e ela não se sentia bem. Procurei conversar com os alunos e explicar a dificuldade dela, mostrando que todos poderiam ajudar com aquela situação. Todos poderiam ajudar fazendo as tarefas juntos, conversando e não agindo daquela forma que apenas a deixava triste e isolada. Acho que resolveu. 
Prof.4:

Formação: 30

Atuação: 30
Tem casos que podemos resolver na própria sala de aula, mas outros que devemos levar para os gestores, coordenação para que eles façam alguma coisa, chamar os pais para uma conversa (...) a família tem que ajudar nessa hora. Teve um caso de uma aluna do norte, que falava de um jeito diferente e os alunos zombavam dela. Mostrei que o jeito dela falar, tinha a ver com a sua cultura ... a cultura da região dela. E que nós poderíamos aprender coisas legais com ela. A partir desse momento, ela passou a compartilhar algumas expressões com a sala e ficou até gostoso, foi lúdico, interessante... todos participaram, foi bem legal... o "muro" que separava eles, parece que foi quebrado. A menina passou inclusive a falar mais na sala.
Prof.5: Formação:04 Atuação: s/ dado

Acho que da mesma forma, intervenção através de um diálogo, muita conversa mostrando que essa prática não acrescenta nada e apenas separa os amigos (...) sinto que o que falta hoje em dia é essa conversa, sabe? O diálogo franco e aberto para minimizar os conflitos.

Prof.6:

Formação: 05 Atuação: 05

Prof.7:

Formação: 08

Atuação: 08

Como disse o caso do aluno homossexual... precisei parar tudo e colocar ordem na casa... reunir o pessoal, conversar. Acho que com os adolescentes o diálogo funciona muito bem.

Houve um caso bem interessante de um aluno nordestino, que falava de um jeito diferente...eu particularmente achava bem interessante culturalmente falando, mas os alunos zombavam dele por causa do jeito de falar e de certas expressões que ele utilizava no dia a dia. Precisei ser enérgico com a turma, porque isso era geral. Percebi que o garoto não gostava dessa coisa de ficar sendo ridicularizado...e então repreendi a sala... dei uma dura... de vez em quando é bom, né? E passei a orientar a sala, falei sobre empatia, se colocar no lugar do outro, foi bem legal...

Prof.8:

Formação: 05 Atuação: 05
Olha...nunca percebi nada assim tão grave, mas sempre que percebo algo diferente, oriento na hora.

\section{Quadro 6 - Escola II - Atitudes dos professores frente a práticas de bullying envolvendo adolescentes}

Prof.1:

Formação: 24

Atuação: 23

Já aconteceu... Chamar a atenção, abrir uma roda de conversa...levantar as diferenças das pessoas que estão ali. Chamar a atenção das pessoas que estão ali... muitas vezes a criança que é vitimada já vem chorando...Então devemos perguntar aos demais: Por que você fez isso? AH! Porque ela é gorda mesmo. Então pergunto: Você não acha que tem defeitos? Por que você tá falando assim? Na roda de conversa você abre para o grupo. É legal o que você tá fazendo com seu colega? Não precisa fazer assim. É mais ou menos esse caminho.

Prof.2:

Formação: 06

Conversaria com os envolvidos e buscaria Atuação: 06 apaziguar os ânimos, mostrando que este tipo de coisa apenas prejudica e não acrescenta nada a vida de ninguém...acho que a conversa com os adolescentes pode ajudar em muito. Eles até que ouvem os professores, mas primeiro temos que conquistá-los, mostrar pra eles que queremos o bem de cada um.

Prof.3:

Formação: 11 Já aconteceu sim... procuro sempre con-

Atuação: 11 versar, né? Acredito que ocorre bullying o tempo todo, mas eles nem sempre conversam com os professores, acabam sofrendo em silêncio... as agressões podem ocorrer também na hora do intervalo, ou até mesmo fora da escola, mas quando acontece na sala de aula, temos que fazer alguma coisa.

Prof.4:

Formação: 10

Atuação: 10

Tivemos uma vez uma garota que se vestia só de preto, era gótica, roqueira...coisa assim. Ah! O pessoal não perdoava, chamavam ela de mortiça Adams, viúva negra... ela no começo até ria, mas um dia se irritou, ficou nervosa mesmo ... deu uns gritos ....foi bem chato. Aí percebemos que deveríamos tratar o assunto com mais firmeza (...) Bom... eu na verdade, prefiro chamar os envolvidos no canto e orientá-los, conversar, ver o que está acontecendo entre eles. Agir como uma mediadora, facilitando o entendimento entre eles.

Prof.5:

Formação 20:

Atuação: 20
Acho que isso acontece todos os dias, quando percebo chamo para uma conversa. Se eu fico sabendo, na hora eu repreendo, chamo a atenção e bato um papo com que está envolvido.

Prof.6:

Formação: 25

Atuação: 25
Acho que acontece todo o santo dia, mas nem sempre ficamos sabendo, mas minha atitude seria estabelecer um diálogo entre eles para resolver a questão de uma forma bem amigável e construtiva.

Chamaria em um canto para conversar e ver o que estava acontecendo e em seguida procuraria mediar a situação. 


\begin{tabular}{|l|l|}
\hline $\begin{array}{l}\text { Prof.7: } \\
\text { Formação: 04 } \\
\text { Atuação: 04 }\end{array}$ & $\begin{array}{l}\text { Acho que ocorre, mas nada tão gritante } \\
\text { assim...minha atitude é sempre a conversa. } \\
\text { Chamo a atenção e oriento. } \\
\text { Se acontecesse veria o que está acontecen- } \\
\text { do e chamaria os envolvidos para uma con- } \\
\text { versa. Não deixaria a coisa para o outro dia. }\end{array}$ \\
\hline $\begin{array}{l}\text { Prof.8: } \\
\text { Formação: 03 } \\
\text { Atuação: 03 }\end{array}$ & $\begin{array}{l}\text { Acho que isso (bullying) ocorre a todo o } \\
\text { momento, mas nem sempre é algo que } \\
\text { ficamos sabendo, por isso temos que tra- } \\
\text { balhar na conscientização dos alunos. }\end{array}$ \\
\hline
\end{tabular}

e) Preparo dos professores e equipe escolar para lidarem com o bullying entre adolescentes

A maioria dos entrevistados afirmou que os professores não estão preparados para lidar com o bullying entre adolescentes. Esta afirmação deve-se muito provavelmente ser oriunda da expectativa que os entrevistados possuem que o docente desenvolva, durante o exercício de sua prática pedagógica, a habilidade na resolução de conflitos entre alunos, pois os atritos são frequentes, cabendo ao professor posicionar-se para minimizar o conflito e dar continuidade ao seu trabalho, muitas vezes de uma forma mais intuitiva, simplista e solitária, isto é, sem se fundamentar na legislação e ou na literatura a respeito e mesmo contar com o apoio da equipe pedagógica e/ ou escolar como um todo.

No que se refere ao preparo da equipe escolar aqui considerada como composta por diretores, coordenadores, monitores, porteiros, pessoal de secretaria entre outros profissionais -, de acordo com os professores, as respostas mais frequentes foram "acho que não" e "não sei", o que nos leva a entender que as equipes das escolas estudadas, de modo geral, não se mostravam preparadas para lidar com o fenômeno bullying, uma vez que suas ações nesse sentido não eram expressadas, comunicadas e, portanto, não reconhecidas pelos professores como efetivas, apontando para um problema de comunicação a ser considerado, a fim de ser resolvido nas duas escolas, conforme é possível observar nos Quadros 7 e 8 a seguir:

\section{Quadro 7 - Escola I: Preparo dos professores e equipe escolar para lidarem com o bullying entre adolescentes}

Prof.1: $\quad$ Professores: Na verdade....acho que não Formação: 08 somos preparados para lidar com essas Atuação: 08 questões.

Equipe escolar: Nunca soube de nenhum curso ou atividade sobre este tema na escola, a não ser conversa na sala dos professores.

Prof.2:

Formação: 21

Professores: Não. Acho que não.

Atuação: 11

Equipe escolar: Olha...não sei mesmo.

Não tenho esse registro.

Prof.3:

Formação: 20

Atuação: 10

Professores: Não.

Equipe escolar: Acho que diretores e coordenadores, sim. Os demais funcionários da área de secretaria e portaria não. Cada um participa das reuniões de sua área... eu acho.

Prof.4:

Formação: 30

Professores: Não.

Atuação: 30

Equipe escolar: Acho que só aqueles professores e coordenadores envolvidos no ensino fundamental..

Prof.5:

Formação:04

Atuação: s/

dado

Professores: Não! Não estão!

Preparo: Debates nas ONGs em que trabalhei. Na escola: Já(teve). Foi bem satisfatório

Equipe: Acho que não.

Prof.6:

Formação: 05

Professores: Olha...depende do tempo

Atuação: 05 porque os professores mais antigos têm juma visão mais de disciplina e aplicação de conteúdo... acho que não possuem essa preocupação em relação às mudanças da sociedade... querem dar aula, aula... e os alunos ficam em segundo plano.

Preparo: Já (teve). Foi na verdade uma palestra voltada para educadores, duração de mais ou menos duas horas, mas gostei, foi bem didática.

Equipe escolar: Não sei, viu...não tenho esta informação. Não sei mesmo... acho que recebem cursos para as áreas de gestão, de secretaria...acho que é isso.

Prof.7:

Formação: 08 Atuação: 08
Professores: Não, não estão.

Preparo: Já (teve)! Foi uma conversa, uma palestra de mais ou menos uma hora e meia ministrada pelo próprio coordenador da escola. Foi bem legal, os professores falaram de seus casos na sala de aula, foi breve, mas bem proveitosa.

Equipe escolar: Acho que os coordenadores e talvez os diretores sim, mas o resto dos funcionários acho que não.

Prof.8:

Formação: 05

Atuação: 05
Professores: Não.

Equipe escolar: Não sei dizer se eles participam de treinamentos sobre isso. 


\section{Quadro 8 - Escola II: Preparo dos professores e equipe escolar para lidarem o bullying entre adolescentes}

\begin{tabular}{|c|c|}
\hline $\begin{array}{l}\text { Prof.1: } \\
\text { Formação: } 24 \\
\text { Atuação: } 23\end{array}$ & $\begin{array}{l}\text { Professores: Não! Não estão preparados, } \\
\text { acho que falta muito ainda na graduação, } \\
\text { pós-graduação. Esse assunto tem que ser } \\
\text { levando muito mais a sério. Ouvi falar de } \\
\text { bullying na pós-graduação em } 2008,2009 \text {. } \\
\text { Equipe escolar: Olha agora, por conta da } \\
\text { mídia a prefeitura está falando mais disso, } \\
\text { eles estão mais voltados para isso, mas eu } \\
\text { não vejo isso sendo divulgado dentro da } \\
\text { escola. }\end{array}$ \\
\hline $\begin{array}{l}\text { Prof.2: } \\
\text { Formação: } 06 \\
\text { Atuação: } 06\end{array}$ & $\begin{array}{l}\text { Professores: Não. Acho que não. } \\
\text { Equipe escolar: Acho que não. }\end{array}$ \\
\hline $\begin{array}{l}\text { Prof.3: } \\
\text { Formação: } 11 \\
\text { Atuação: } 11\end{array}$ & $\begin{array}{l}\text { Professores: Acho que alguns sim ... a } \\
\text { maioria não. } \\
\text { Equipe escolar: Olha...não sei dizer... } \\
\text { acho que eles não recebem capacitação } \\
\text { sobre isso não. Acho que só recebem } \\
\text { capacitaçães sobre gestão, parte burocrática } \\
\text { e administrativa. }\end{array}$ \\
\hline $\begin{array}{l}\text { Prof.4: } \\
\text { Formação: } 10 \\
\text { Atuação: } 10\end{array}$ & $\begin{array}{l}\text { Professores: Acho que não. Precisamos de } \\
\text { mais informação sobre esse tema. } \\
\text { Equipe escolar: Acho que não recebem } \\
\text { nenhuma capacitação sobre o tema. }\end{array}$ \\
\hline $\begin{array}{l}\text { Prof.5: } \\
\text { Formação 20: } \\
\text { Atuação: } 20\end{array}$ & $\begin{array}{l}\text { Professores: No momento acho que não. } \\
\text { Equipe escolar: Acho que recebem } \\
\text { capacitação, mas sobre temas relacionados } \\
\text { à gestão, parte administrativa, novas leis, } \\
\text { questões burocráticas...sobre bullying, acho } \\
\text { que não recebem, não. }\end{array}$ \\
\hline $\begin{array}{l}\text { Prof.6: } \\
\text { Formação: } 25 \\
\text { Atuação: } 25\end{array}$ & $\begin{array}{l}\text { Professores: Hoje não! } \\
\text { Preparo: Uma vez fui a uma palestra sobre } \\
\text { este tema em um evento de uma faculdade. A } \\
\text { escola fez uma vez uma palestra com alunos } \\
\text { de uma faculdade de pedagogia. Foi bem } \\
\text { legal. } \\
\text { Equipe escolar: Acho que recebem, mas } \\
\text { nunca fiquei sabendo exatamente se isso } \\
\text { acontece. }\end{array}$ \\
\hline $\begin{array}{l}\text { Prof.7: } \\
\text { Formação: } 04 \\
\text { Atuação: } 04\end{array}$ & $\begin{array}{l}\text { Professores: Acho que não. } \\
\text { Preparo: Participei de uma palestra em uma } \\
\text { escola. } \\
\text { Equipe escolar: Não sei se eles recebem este } \\
\text { tipo de treinamento... acredito que não. }\end{array}$ \\
\hline $\begin{array}{l}\text { Prof.8: } \\
\text { Formação: } 03 \\
\text { Atuação: } 03\end{array}$ & $\begin{array}{l}\text { Professores: Olha, pelo que eu percebo não. } \\
\text { Preparo: Uma palestra, uma vez, de duas } \\
\text { horas mais ou menos. Eu gostei sim, foi bem } \\
\text { esclarecedora. Equipe escolar: Acredito que } \\
\text { não. }\end{array}$ \\
\hline
\end{tabular}

\section{f) Orientações e/ou protocolos institucionais a serem seguidos pelos professores e equipe escolar em casos de bullying na escola.}

Quanto a esta questão, as escolas não estavam preparadas para orientar professores e pais, bem como apresentar projetos e/ou programas de atendi- mento a todos os envolvidos em situações de violência na escola, em especial o bullying, e em relação a sua distinção de outras formas de violência na escola, bem como ao que deve ser feito e ao como fazer, conforme determinam, atualmente, as duas Leis Federais que visam a erradicação do bullying - a Lei $n^{\circ} 13.185 / 2015$ e a Lei $n^{\circ} 13.633 / 2018$ - sendo que esta última, inclusive, altera a Lei de Diretrizes e Bases da Educação Nacional - Lei 9394/1996, em razão deste fenômeno.

As respostas dadas pelos professores, conforme podemos observar nos Quadros 9 e 10, assim como na questão anterior, também demonstram o desconhecimento em relação à existência de orientações e/ ou protocolos em suas instituições de ensino, pelos quais poderiam se orientar para juntos encontrarem melhores maneiras de lidar com os casos de bullying.

\section{Quadro 9 - Escola I: Orientações e/ou protocolos institucionais a serem seguidos pelos professores e equipe escolar em casos de bullying na escola}

Prof.1:

Formação: 08 conversam com os envolvidos. Acho que em Atuação: 08 alguns casos até o Conselho Tutelar deveria ser chamado, mas não sei o que acontece depois.

Prof.2: $\quad$ Não sei dizer.

Formação: 21

Atuação: 11

Prof.3: $\quad$ Acho que não! A meu ver ... acho que

Formação: 20 apenas os pais e os responsáveis são

Atuação: 10 chamados e fica por isso mesmo ... Não sei nem se isso é feito.

Prof.4: $\quad$ Não sei direito, mas acho que dependendo

Formação: 30 do caso, se for alguma coisa muito grave, a Atuação: 30 direção... eles encaminham para o Conselho Tutelar, eu acho.

Prof.5: $\quad$ Não sei.

Formação:04 Atuação: s/ dado

Prof.6:

Formação: 05 Atuação: 05

Olha...não sei...Não tenho certeza desses procedimentos mais administrativos, mas acho que em primeiro lugar os pais são chamados pra conversar, tentar resolver a situação, mas dependendo do caso, acho que até vão para o Conselho Tutelar... isso em casos mais graves, mas sério...acho nunca nem aconteceu assim... não tenho certeza.

\section{Prof.7:}

Não sei sobre isso. Não sei o que eles fazem, Formação: 08 não.

Atuação: 08

\section{Prof.8:}

Não sei.

Formação: 05

Atuação: 05 


\section{Quadro 10 - Escola II: Orientações e/ou protocolos institucionais a serem seguidos pelos professores e equipe escolar em casos de bullying na escola}

\begin{tabular}{|l|l|}
\hline $\begin{array}{l}\text { Prof.1: } \\
\text { Formação: } 24 \\
\text { Atuação: } 23\end{array}$ & $\begin{array}{l}\text { Acho que não! Não temos muitos mecanismos, } \\
\text { além da conversa... Não tem a quem recorrer, } \\
\text { nem sabemos direito a quem recorrer. }\end{array}$ \\
\hline $\begin{array}{l}\text { Prof.2: } \\
\text { Formação: } 06 \\
\text { Atuação: } 06\end{array}$ & Não sei mesmo. \\
\hline $\begin{array}{l}\text { Prof.3: } \\
\text { Formação: } 11 \\
\text { Atuação: } 11\end{array}$ & $\begin{array}{l}\text { Acho que não...e não sei o que a escola faz exa- } \\
\text { tamente. Acho que no mínimo chamam os pais. }\end{array}$ \\
\hline $\begin{array}{l}\text { Prof.4: } \\
\text { Formação: } 10 \\
\text { Atuação: } 10\end{array}$ & Não sei ao certo quais caminhos eles percorrem. \\
\hline $\begin{array}{l}\text { Prof.5: } \\
\text { Formação } 20: \\
\text { Atuação: } 20\end{array}$ & $\begin{array}{l}\text { Não sei ao certo. Acho que dependendo do caso, } \\
\text { chamam os pais. }\end{array}$ \\
\hline $\begin{array}{l}\text { Prof.6: } \\
\text { Formação: } 25 \\
\text { Atuação: } 25\end{array}$ & Não sei. \\
\hline $\begin{array}{l}\text { Prof.7: } \\
\text { Formação: } 04 \\
\text { Atuação: } 04\end{array}$ & Não sei. \\
\hline $\begin{array}{l}\text { Prof.8: } \\
\text { Formação: } 03 \\
\text { Atuação: } 03\end{array}$ & $\begin{array}{l}\text { Acredito que não...acho que no máximo, chamam } \\
\text { os pais dos envolvidos para uma conversa, se o } \\
\text { caso foi muito grave. }\end{array}$ \\
\hline
\end{tabular}

\section{Considerações finais}

Observamos consenso entre os entrevistados a respeito de que, nas instituições em que trabalhavam, o conhecimento sobre o bullying não estava na pauta das reuniões, treinamentos e outras formas de atualização, assim como, o apoio para a resolução dos conflitos (dele resultantes) no âmbito da escola, indicando, uma importante lacuna a ser preenchida quanto à atualização profissional dos professores e equipe escolar. Ao pesquisarem o bullying escolar, Zequinão et al. (2016) encontraram que, embora muitas vítimas não relatem nada a ninguém, entre aquelas que o fazem, em primeiro lugar, procuram seus pais ou responsáveis e, em segundo, procuram os professores ou diretor/a da escola. Neste sentido, é importante considerar que os professores, depois dos pais ou responsáveis, são as primeiras fontes de confiança e proteção para crianças e adolescentes que optam por relatar as situações de bullying pelo qual se sentem vitimizados.

Pelo relato dos professores das duas escolas, ainda que, sem generalizar, foi possível observar perfis de adolescentes mais suscetíveis de serem vitimizados, tais como os obesos, os homossexuais, os que procuram se diferenciar de alguma forma, os que são excluídos pelo seu jeito idiossincrático de ser e se expressar, fruto de sua cultura raiz como, por exemplo, os nordestinos.

Além de conhecimento mais consistente a respeito da legislação e a respeito dos aspectos conceituais do fenômeno e suas consequências negativas em curto, médio e longo prazos, os profissionais necessitam de maior apoio para o enfrentamento do bullying em seu ambiente de trabalho; talvez uma forma, possível, para dar início à resolução de conflitos a curto prazo seria a promoção de oficinas e workshops em que pudessem criar, juntos, orientações a serem veiculadas entre os próprios professores e equipe escolar e, em seguimento, estendidas aos alunos, pais ou responsáveis, quanto às formas de prevenção e quanto ao envolvimento de adolescentes em casos de bullying. No entanto, algumas formas de capacitação para o enfrentamento apenas em curto e médio prazos não se sustentam depois de um certo tempo. É preciso a realização de ações permanentes de conscientização e de aplicação a longo prazo. Todos necessitam entender que o bullying é um tipo de violência e é uma forma grave de violência que pode e deve ser erradicada!

Estamos cientes das limitações do estudo realizado, contudo, as questões levantadas apontam para alguns rumos importantes que não podem ser negligenciados pela sociedade e pelo poder público. Cada vez mais, torna-se importante investir na formação humanística dos profissionais que atendem e atenderão crianças e adolescentes. Não basta apenas ter uma preocupação estritamente de produção de resultados, faz-se necessário um olhar mais humanizador, uma postura mais voltada às questões psicossociais, entendendo o ser humano como um ser integral. Assim:

- Família, escola e poder público são responsáveis pela educação de qualidade, devem andar de mãos dadas e, juntos, (ainda que) minimamente, promover o melhor enfrentamento das dificuldades.

- As instituições necessitam agir de forma articulada, de acordo com protocolos específicos (onde se possa seguir um programa passo a passo e que 
oriente quais ações a serem tomadas) que ofereçam suporte aos professores e equipe escolar, considerem as necessidades dos adolescentes e em conjunto trabalhem para a prevenção e erradicação do fenômeno da violência nas escolas e, em especial, o bullying.

- O estudo demonstrou que as instituições participantes, não possuem protocolos e programas específicos de prevenção e atendimento ao adolescente envolvido em casos de bullying. Seria necessário, portanto, a construção coletiva e intersetorial (Universidade, escolas e equipes multiprofissionais) de protocolos que atendam a realidade local.

- Os cursos de formação de professores, bem como de médicos pediatras, assistentes sociais, psicó- logos e tantos outros profissionais que, por ventura, venham a atender adolescentes, necessitam rever suas matrizes curriculares, atualizando-as de acordo com as necessidades e mudanças sociais. Oportunamente, os currículos devem ser discutidos e constantemente revisados, visando a atender essas demandas sociais da contemporaneidade, principalmente no que diz respeito ao universo dos adolescentes.

- As áreas da Saúde e educação necessitam dialogar com mais frequência. Neste sentido, o pioneirismo do Programa de Pós-graduação em Educação e Saúde na Infância e Adolescência / Unifesp cumpre um importante papel na formação de profissionais qualificados na promoção e articulação entre saúde e educação.

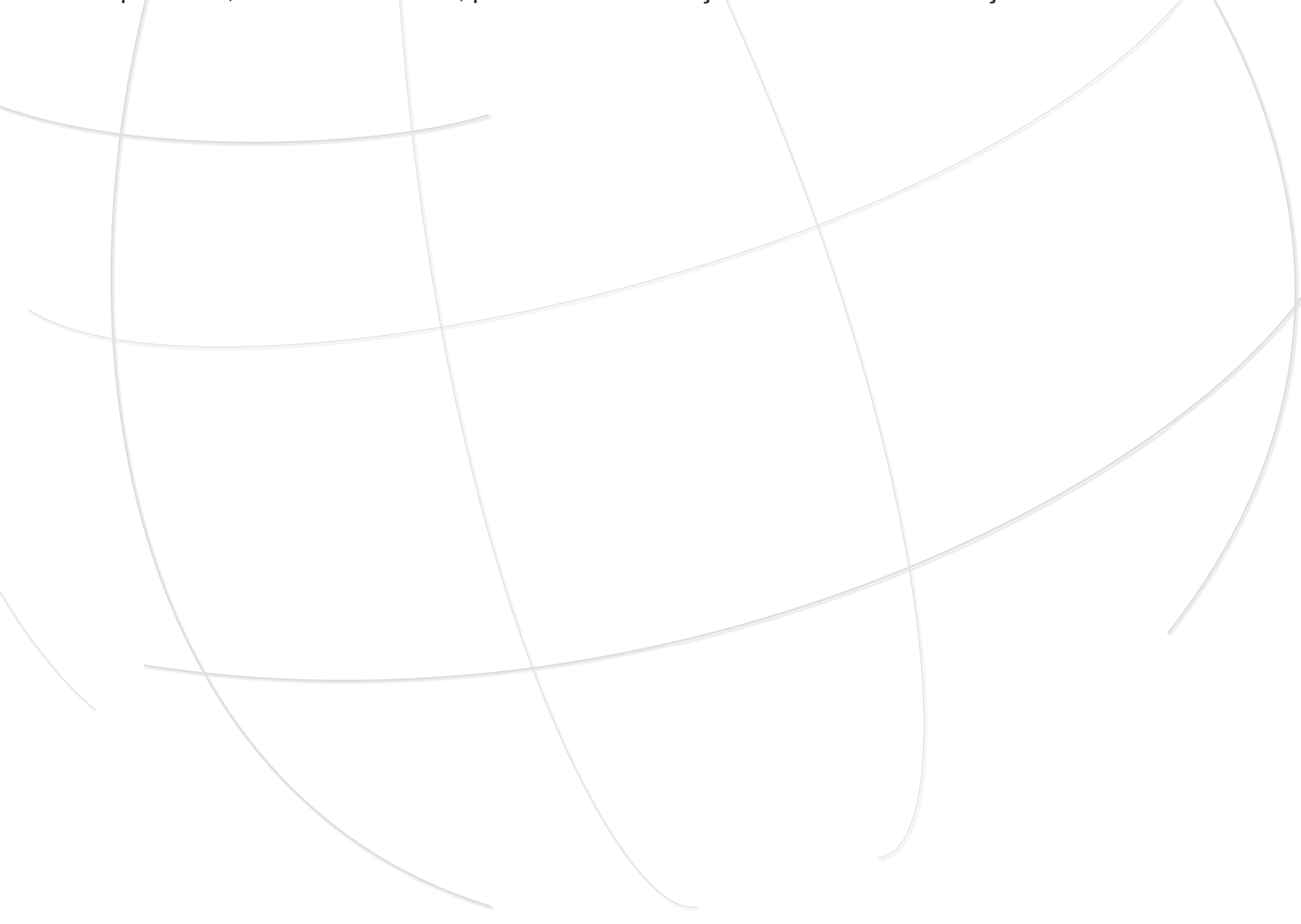




\section{REFERÊNCIAS}

ABRAMOVAY, Miriam; CASTRO, Mary Garcia. Caleidoscópio das violências nas escolas. Brasília: Missão Criança, 2006.

BARDIN, Laurence. Análise de Conteúdo. São Paulo: Edições 70 LDA/Almedina Brasil, 2011.

BERTO, David Marcelo P. Violência contra professores não pode ser vista como algo normal. São Pauo: Centro do professor Paulista, 2018. Disponível em: https://www.cpp.org.br/informacao/ponto-vista/item/12839-violencia-contra-professores-nao-podeser-vista-como-algo-normal Acesso em 06 maio 2019.

BRASIL. Lei Federal $\mathbf{n}^{\circ} \mathbf{9 . 3 9 4}$, de 20 dezembro de 1996. Estabelece as diretrizes e bases da educação nacional. Brasília: Diário Oficial da União, 1996.

BRASIL. Lei Federal $n^{\circ} 13.185$ de 06 de novembro de 2015. Institui o Programa de Combate à Intimidação Sistemática (Bullying).

BRASIL. Lei Federal $n^{0} 13.633$ de 14 de maio de 2018. Altera o art. 12 da LDB Lei n 9.394/96.

CEATS/FIA - Centro de Empreendedorismo Social e Administração em Terceiro Setor / Fundação Instituto de Administração. Bullying escolar no Brasil: Relatório Final. São Paulo, 2010.

GIORDANI, Jaqueline Portella; SEFFNER, Fernando; DELL>AGLIO, Débora Dalbosco. Violência escolar: percepções de alunos e professores de uma escola pública. Psicol. Esc. Educ. [online], v. 21, n.1, p.103-111, 2017.

MARCOLINO, Emanuelle de Castro; CAVALCANTI, Alessandro Leite; PADILHA, Wilton Wilney Nascimento et al. Bullying: Prevalência e Fatores Associados à Vitimização e à Agressão no Contexto Escolar. Texto e Contexto Enferm, v. 27, n. 1, 2018.

PARANAHIBA, Tales Alves; PARANAHIBA, Taís Alves. O uso do ECA no combate ao bullying. Revista Jurídica do Ministério Público do Estado do Paraná, ano 3, n 5, p. 373-387, dez, 2016.

PEDROSO, Glaura César. Bullying. In: VITALLE, MSS. (Ed.): Medicina do Adolescente: fundamentos e prática. São Paulo: Atheneu, 2019, p 505-508.
RICCIARDI, Andréa. Reações de Enfrentamento Possíveis, dos Professores de Ensino Fundamental II, ao Bullying Escolar: Um olhar sobre Tabus. Dissertação (Mestrado em Ciências), 2013. 131 f. São Paulo: Unifesp, 2013.

SANTOS, Maria de Lourdes. Uma Discussão sobre o Bullying para uma Sociedade sem Ameaças, Intimidações e Humilhações. Monografia. João Pessoa: UFPB; p. 33. 2014.

SILVA, Jorge Luiz da; OLIVEIRA, Wanderlei Abadio de; BAZON, Marina Resende; et al. Bullying: conhecimento, atitudes e crenças de professores. Rev. Psico, v. 45. n. 2, p 147-156, abril-junho 2019.

UNESCO. Novo Relatório da UNESCO sobre Violência Escolar e Bullying é lançado em Simpósio Internacional sobre questão que afeta milhões em todo o mundo. Brasília: Unesco, 2017. Disponível em: http://www.unesco.org/new/pt/brasilia/aboutthis-office/single-view/news/new unesco report_on school violence and bullying to be rele/, Acesso em 07 maio 2019.

VITALLE Maria Sylvia de Souza, SCHOENFERREIRA Teresa Helena, WEILER Rosa Maria Eid et al. O Setor de Medicina do Adolescente (Centro de Atendimento e Apoio ao Adolescente - CAAA) da Universidade Federal de São Paulo: uma experiência multiprofissional e interdisciplinar - o compromisso com a adolescência. Adolesc Saúde, v. 7, n. 4, p. 13-20, 2010.

ZEQUINÃO, Marcela Almeida; MEDEIROS, Paula de; PEREIRA, Beatriz; CARDOSO, Fernando Luiz. Bullying Escolar: um fenômeno multifacetado. Educ. Pesqui, v. 42, n. 1, p. 181-198, jan/mar. 2016.

Agradecimento:

Às Escolas e aos professores participantes do nosso estudo. 